\title{
Adherence to Therapeutic Regimen in Diabetic Patients Attending a Tertiary Level Hospital
}

\author{
Krishna D Shrestha, Takma KC, Rachana Ghimire \\ Department of Adult Nursing/Medical Surgical Nursing, Maharajgunj Nursing Campus, Institute of Medicine, \\ Tribhuvan University, Kathmandu, Nepal
}

\section{Corresponding author:}

\section{Krishna D Shrestha, BN, MN}

Department of Adult Nursing/Medical Surgical Nursing, Maharajgunj Nursing Campus, Institute of Medicine, Tribhuvan University, Kathmandu, Nepal

Email: krishna_kr06@yahoo.com

Submitted : May 24, 2020

Accepted : July 7, 2020

\begin{abstract}
Introduction

Adherence to treatment regimen among diabetes patients is very crucial for good glycemic control. Poor adherence is a widely recognized problem causing great impact on poor health outcomes and healthcare costs. Hence, this study was conducted to identify the adherence to prescribed therapeutic regimen among diabetic patients.
\end{abstract}

\section{Methods}

A descriptive cross sectional research design was adopted. Data was collected purposively among 422 respondents attending at medical OPD in Tribhuvan University Teaching Hospital through interview using structured questionnaire. Analysis was done by descriptive and inferential statistics.

\section{Results}

The study findings revealed good follow up adherence (57.8\%). Adherence to medicine, diet and exercise were $(28.5 \%),(16.1 \%)$ and $(8.8 \%)$ respectively. Dietary adherence was associated with sex $(p=0.03)$, educational level $(p<0.001)$, occupation $(p=0.04)$, attending diabetic counseling $(p<0.001)$ and knowledge level $(p<0.001)$. Exercise adherence was associated with sex, educational level, attending diabetic counseling, history of hospitalization and knowledge level $(p<0.05)$. Medication adherence was associated with attending diabetic counseling $(p=0.03)$. Follow up adherence was associated with education, occupation, attending diabetic counseling, duration of diabetes mellitus, frequency of follow up visit, and knowledge level $(p<0.05)$. Moreover, respondents with good adherence to exercise $(75.7 \%)$, medicine (63.3\%) and follow up adherence (66\%) had controlled fasting blood sugar level $(p=0.01, p=0.03$ and $\mathrm{p}=0.01$ respectively).

\section{Conclusion}

Adherence on diet and exercise was very low than other components among diabetes patients. So, it is recommended to focus on education especially on diet and exercise adherence which would be of great benefit in glycemic control.

Keywords: Adherence, compliance, diabetic patient, treatment regimen 


\section{INTRODUCTION}

T he prevalence of type 2 diabetes mellitus (DM) is increasing globally and is one of the major public health challenges faced at present by the world. ${ }^{1}$ International Diabetes Federation [IDF] reported that worldwide approximately 463 million adults were living with diabetes; by 2045 this will rise to 700 million. $^{2}$ In the IDF South-East Asia (SEA) Region, 88 million people are living with diabetes in 2019, 57\% diabetic people are undiagnosed and 1.2 million died due to diabetes. ${ }^{3}$ Nepal is one of the seventh countries of the IDF SEA region with $4 \%$ prevalence of diabetes in adults with 696,900 cases. ${ }^{4}$ Seventy nine percent of adults with diabetes were living in low and middle-income countries. $^{2}$

According to the World Health Organization (WHO), adherence to therapy is defined as "the extent to which a person's behavior in taking medication, following a diet, and/or executing lifestyle changes, corresponds with agreed recommendations from a healthcare provider". The adherence to long-term therapy for chronic illnesses in developed countries averages only around $50 \% .{ }^{5}$ Studies revealed that the prevalence of poor adherence to treatment is approximately $36-93 \% .^{6}$ A study conducted among Nepalese type 2 DM patients showed that $87.5 \%$ were non adherent and $12.5 \%$ were poorly adherent to diet, and $42.1 \%$ were non- compliance to exercise. ${ }^{7}$

Adherence to treatment plan of diabetes is complex. Improve adherence to treatment is to improve glycemic control. ${ }^{8}$ Kalyango, Owino and Nambuya mentioned that no improvement of metabolic control is possible without patient's compliance. ${ }^{9}$ WHO stated that reduced adherence not only results in poor health outcomes but it also has a significant impact on healthcare costs. ${ }^{5}$ In Nepalese context, diabetes has become an increasingly prevalent ${ }^{10}$ and very few studies had been conducted regarding adherence to different therapeutic regimen. Therefore, this study aims to identify the level of adherence of therapeutic regimen and its association with selected variables among diabetic patient that helps to recommend appropriate interventions for improving compliance, controlling the blood sugar level and preventing chronic complications.

\section{METHODS}

A descriptive cross sectional study was conducted among 422 diabetic patients at Tribhuvan University Teaching Hospital (TUTH). Non probability purposive sampling technique was adopted. Patients diagnosed as type 2 DM, on treatment for 3 month and more attending at Medical endocrine OPD day were included in this study. Data was collected after approval from Institutional Review Committee of
Institute of Medicine, Tribhuvan University. Written permission was obtained from the TUTH, informed written consent was taken from each respondent. Voluntary participation and withdrawal from the study in any time were considered. Confidentiality was maintained by using code number in each form and respondents were assured for not disclosing the information.

Data was collected from December 2017 to March 2018 by using structured questionnaire with interview on adherence to therapeutic regimen which includes patients' behaviors in terms of following diet, exercise, taking medicine and follow up advice as per the health care providers' recommendation to control blood sugar. Morisky Medication Adherence scale (MMAS -8)11 was used to measure medication adherence. The level of adherence was categorized as good (>75\% score), fair (50-75\% score) and poor (<50\% score), 1 Fasting blood sugar (FBS) was used to assess Glycemic control. Further, it was categorized as good glycemic control (FBS $=\leq 130 \mathrm{mg} / \mathrm{dl}$ ) and poor glycemic control ( $\mathrm{FBS}=>130 \mathrm{mg} / \mathrm{dl}$ ) based on American Diabetes Association (ADA) Diabetes Guideline Summary Recommendation, 2016.12 The validity of the instrument was established by consulting with Head of Department of Internal Medicine and Unit Chief, senior dietician, subject experts and reviewing the related literature. The collected data was entered into SPSS version 16 and analysis was done by using descriptive and inferential statistics. A p value of $<0.05$ was assumed to be statistically significant.

\section{RESULTS}

More than half of the respondents (53.8\%) were between the age of $41-60$ years, $53.6 \%$ were female, $24.9 \%$ had secondary level education, $30.8 \%$ were homemaker. Majority of respondents (85.1\%) were from urban area and $42.9 \%$ had family history of diabetes mellitus.

Respondents' adherence to therapeutic regimen in

Table 1. Respondents' level of adherence to therapeutic regimen

\begin{tabular}{lccc}
\hline \multirow{2}{*}{ Variables } & \multicolumn{3}{c}{ Level of Adherence } \\
\cline { 2 - 4 } & Good & Fair & Poor \\
\hline Dietary adherence & 68 & 282 & 72 \\
& $(16.1 \%)$ & $(66.8 \%)$ & $(17.1 \%)$ \\
Exercise adherence & 37 & 65 & 320 \\
& $(8.8 \%)$ & $(15.4 \%)$ & $(75.8 \%)$ \\
Medicine adherence & 115 & 289 & 0 \\
(n=404) & $(28.5 \%)$ & $(71.5 \%)$ & $(0 \%)$ \\
Follow up adherence & 244 & 70 & 108 \\
& $(57.8 \%)$ & $(16.6 \%)$ & $(25.6 \%)$ \\
\hline
\end{tabular}


four different areas i.e diet, exercise, medicine and follow up were assessed. Study findings showed more than half of the respondents (57.8\%) had good adherence in follow up, $28.5 \%$ respondents had good adherence in medicine. Only $16.1 \%$ and $8.8 \%$ had good adherence in diet and exercise respectively (Table 1 ). Male respondents (20.9\%), having higher education (29.5\%) and those involved in service $(26.4 \%)$ had good dietary adherence. There was the significant association between sex, education, occupation, attended diabetic counseling and knowledge level on diabetes with dietary adherence $(p<0.05)$ (Table 2). Exercise adherence was significantly associated with sex $(p<0.001)$, educational level $(p=0.01)$, respondents attended in diabetic counseling $(p<0.001)$, history of hospitalization due to diabetes mellitus $(p=0.04)$, and level of knowledge $(p<0.001)$ (Table 3 ).

Regarding medicine adherence, among 422 respondents, only 404 respondents were under diabetic medication and adherence to medication was only associated with respondents who had attended in diabetic counseling $(p=0.03)$ in which $25 \%$ respondents who had attended diabetic counseling had good adherence. In follow up adherence, only significantly associated variables are shown in table which depicts follow up adherence was associated with education, occupation, duration of diabetes mellitus, frequency of follow up visit, attended diabetic counseling and knowledge level as $p<0.05$ (Table 4).

Regarding glycemic control finding shows respondents with good exercise adherence (75.7\%) had controlled fasting blood sugar level which was statistically significant $(p=0.01)$. Similarly, respondents with fair medicine adherence (63.3\%) and good follow up adherence (66\%) had controlled fasting blood sugar level $(p=0.03$ and $p=0.01$ respectively) (Table 5).

\section{DISCUSSION}

Treatment adherence is important to control blood sugar level and prevent diabetic complications. The

Table 2. Association between dietary adherences and selected variables

\begin{tabular}{|c|c|c|c|c|c|}
\hline \multirow{2}{*}{ Variables } & \multicolumn{3}{|c|}{ Level of Adherence } & \multirow{2}{*}{$\chi^{2}$ value } & \multirow{2}{*}{$p$-value } \\
\hline & Good & Fair & Poor & & \\
\hline \multicolumn{6}{|l|}{ Age in completed years } \\
\hline$\leq 40$ & $12(20.3 \%)$ & $38(64.4 \%)$ & $9(15.3 \%)$ & 3.759 & 0.44 \\
\hline $41-60$ & $34(15 \%)$ & $159(70 \%)$ & $34(15 \%)$ & & \\
\hline$>61$ & $22(16.2 \%)$ & $85(62.5 \%)$ & $29(21.3 \%)$ & & \\
\hline \multicolumn{6}{|l|}{ Sex } \\
\hline Male & $41(20.9 \%)$ & $127(64.8 \%)$ & $28(14.3 \%)$ & 7.121 & $0.03^{*}$ \\
\hline Female & $27(11.9 \%)$ & $155(68.6 \%)$ & $44(19.5 \%)$ & & \\
\hline \multicolumn{6}{|l|}{ Education level } \\
\hline Can't read and write & $6(6.1 \%)$ & $67(68.4 \%)$ & $25(25.5 \%)$ & 23.554 & $<0.001 *$ \\
\hline Primary level & $21(16 \%)$ & $88(67.2 \%)$ & $22(16.8 \%)$ & & \\
\hline Secondary level & $15(14.3 \%)$ & $75(71.4 \%)$ & $15(14.3 \%)$ & & \\
\hline Higher secondary level and above & $26(29.5 \%)$ & $52(59.1 \%)$ & $10(11.4 \%)$ & & \\
\hline \multicolumn{6}{|l|}{ Occupation } \\
\hline Service & $18(26.4 \%)$ & $42(61.8 \%)$ & $8(11.8 \%)$ & 19.342 & $0.04^{*}$ \\
\hline Business & $16(18.4 \%)$ & $57(65.5 \%)$ & $14(16.1 \%)$ & & \\
\hline Agriculture & $5(7.8 \%)$ & $44(68.8 \%)$ & $15(23.4 \%)$ & & \\
\hline Homemaker & $12(9.2 \%)$ & $92(70.8 \%)$ & $26(20 \%)$ & & \\
\hline Retired & $11(23.4 \%)$ & $29(61.7 \%)$ & $7(14.9 \%)$ & & \\
\hline Unemployed & $6(23.1 \%)$ & $18(69.2 \%)$ & $2(7.7 \%)$ & & \\
\hline \multicolumn{6}{|l|}{ Area of Residence } \\
\hline Urban & $61(17 \%)$ & $236(65.7 \%)$ & $62(17.3 \%)$ & 1.636 & 0.44 \\
\hline Rural & $7(11.1 \%)$ & $46(73 \%)$ & $10(15.9 \%)$ & & \\
\hline \multicolumn{6}{|l|}{ Attended diabetic counseling } \\
\hline Yes & $60(22.1 \%)$ & $177(65.3 \%)$ & $34(12.6 \%)$ & 26.380 & $<0.001^{*}$ \\
\hline No & $8(5.3 \%)$ & $105(69.5 \%)$ & $38(25.2 \%)$ & & \\
\hline \multicolumn{6}{|l|}{ Knowledge Level } \\
\hline Adequate (>75\%) & $40(26 \%)$ & $100(64.9 \%)$ & $14(9.1 \%)$ & 53.44 & $<0.001 *$ \\
\hline Moderate (50-75\%) & $22(12 \%)$ & $137(74.9 \%)$ & $24(13.1 \%)$ & & \\
\hline Inadequate (<50\%) & $6(7.1 \%)$ & $45(52.9 \%)$ & $34(40 \%)$ & & \\
\hline
\end{tabular}


Table 3. Association between exercise adherences and selected variables

\begin{tabular}{|c|c|c|c|c|c|}
\hline \multirow{2}{*}{ Variables } & \multicolumn{3}{|c|}{ Level of Adherence } & \multirow{2}{*}{$\chi^{2}$ value } & \multirow{2}{*}{$\mathrm{p}$-value } \\
\hline & Good & Fair & Poor & & \\
\hline $\begin{array}{l}\text { Age in completed years } \\
\leq 40 \\
41-60 \\
>61\end{array}$ & $\begin{array}{l}5(8.4 \%) \\
17(7.5 \%) \\
15(11 \%)\end{array}$ & $\begin{array}{l}6(10.2 \%) \\
33(14.5 \%) \\
26(19.1 \%)\end{array}$ & $\begin{array}{l}48(81.4 \%) \\
177(78 \%) \\
95(69.9 \%)\end{array}$ & 4.61 & 0.33 \\
\hline $\begin{array}{l}\text { Sex } \\
\text { Male } \\
\text { Female }\end{array}$ & $\begin{array}{c}26(13.2 \%) \\
11(4.9 \%)\end{array}$ & $\begin{array}{l}37(18.9 \%) \\
28(12.4 \%)\end{array}$ & $\begin{array}{c}133(67.9 \%) \\
187(82.7 \%)\end{array}$ & 14.38 & $<0.001^{*}$ \\
\hline $\begin{array}{l}\text { Education level } \\
\text { Can't read and write } \\
\text { Primary level } \\
\text { Secondary level } \\
\text { Higher secondary level and above }\end{array}$ & $\begin{array}{c}5(5.1 \%) \\
11(8.4 \%) \\
10(9.5 \%) \\
11(12.5 \%)\end{array}$ & $\begin{array}{c}5(5.1 \%) \\
27(20.6 \%) \\
16(15.3 \%) \\
17(19.3 \%)\end{array}$ & $\begin{array}{c}88(89.8 \%) \\
93(71 \%) \\
79(75.2 \%) \\
60(68.2 \%)\end{array}$ & 16.55 & $0.01 *$ \\
\hline $\begin{array}{l}\text { Occupation } \\
\text { Service } \\
\text { Business } \\
\text { Agriculture } \\
\text { Homemaker } \\
\text { Retired } \\
\text { Unemployed }\end{array}$ & $\begin{array}{l}8(11.8 \%) \\
6(6.9 \%) \\
4(6.3 \%) \\
8(6.2 \%) \\
7(14.9 \%) \\
4(15.4 \%)\end{array}$ & $\begin{array}{l}14(20.6 \%) \\
12(13.8 \%) \\
7(10.9 \%) \\
17(13.0 \%) \\
9(19.1 \%) \\
6(23.1 \%)\end{array}$ & $\begin{array}{c}46(67.6 \%) \\
69(79.3 \%) \\
53(82.8 \%) \\
105(80.8 \%) \\
31(66 \%) \\
16(61.5 \%)\end{array}$ & 12.74 & 0.24 \\
\hline $\begin{array}{l}\text { Area of Residence } \\
\text { Urban } \\
\text { Rural }\end{array}$ & $\begin{array}{l}30(8.4 \%) \\
7(11.1 \%)\end{array}$ & $\begin{array}{c}60(16.7 \%) \\
5(7.9 \%)\end{array}$ & $\begin{array}{c}269(74.9 \%) \\
51(81 \%)\end{array}$ & 3.40 & 0.18 \\
\hline $\begin{array}{l}\text { Attended diabetic counseling } \\
\text { Yes } \\
\text { No }\end{array}$ & $\begin{array}{c}30(11.1 \%) \\
7(4.6 \%)\end{array}$ & $\begin{array}{c}51(18.8 \%) \\
14(9.3 \%)\end{array}$ & $\begin{array}{l}190(70.1 \%) \\
130(86.1 \%)\end{array}$ & 13.58 & $<0.001^{*}$ \\
\hline $\begin{array}{l}\text { History of hospitalization due to DN } \\
\text { Yes } \\
\text { No }\end{array}$ & $\begin{array}{c}14(12.5 \%) \\
23(7.4 \%)\end{array}$ & $\begin{array}{c}10(8.9 \%) \\
55(17.7 \%)\end{array}$ & $\begin{array}{c}88(78.6 \%) \\
232(74.9 \%)\end{array}$ & 6.72 & $0.04^{*}$ \\
\hline $\begin{array}{l}\text { Knowledge Level } \\
\text { Adequate }(>75 \%) \\
\text { Moderate }(50-75 \%) \\
\text { Inadequate }(<50 \%)\end{array}$ & $\begin{array}{c}25(16.3 \%) \\
12(6.6 \%) \\
0\end{array}$ & $\begin{array}{c}35(22.7 \%) \\
24(13.1 \%) \\
6(7.1 \%)\end{array}$ & $\begin{array}{c}94(61 \%) \\
147(80.3 \%) \\
79(92.9 \%)\end{array}$ & 36.30 & $<0.001^{*}$ \\
\hline
\end{tabular}

findings of the present study reveals more than half of the respondents $(57.8 \%)$ had good adherence in follow up and $28.5 \%$ respondents had good medicine adherence. Only $16.1 \%$ and $8.8 \%$ had good adherence in diet and exercise. Similar to this findings, Klinovszky et al. ${ }^{13}$ mentioned that only $13.3 \%$ and $12.4 \%$ of respondents reported adherence to diet and physical exercise respectively. Similarly, Mirahmadizadeh, Khorshidsavar, Seif, and Sharif, ${ }^{14}$ concluded that adherence to medication was only in $13.6 \%$ respondents, in physical activity $10.4 \%$ and adherence to diet was in $17.4 \% .15,16$ According to Parajuli et al. among 385 Nepalese type 2 DM patients $87.5 \%$ were non adherent and $12.5 \%$ poorly adherent to dietary advice, $42.1 \%$ respondents had non- compliance to exercise. ${ }^{7}$ In consistent with present findings Marinho, et al. ${ }^{17}$ reported good adherence to medicine in $93.5 \%$, diet in $29.2 \%$ and exercise in $22.5 \%$ of respondents. Bonger, Shiferaw, \& Tariku ${ }^{18}$ found that $46.3 \%$ of the respondents adhered to physical exercise, $95.7 \%$ to their medications, and $24.1 \%$ adhere to recommended dietary management practices. These discrepancy might be attributed to the difference in lifestyle, the self-reported nature of the data collection method and difference in sample size.

The presentstudy revealed the significantassociation between sex $(p=0.03)$, educational level $(p<0.001)$, occupation ( $(p=0.04)$, attending diabetic counseling $(p<0.001)$, knowledge on diabetes $(p<0.001)$ and dietary adherence in which male respondents (20.9\%), having higher education $(29.5 \%)$ and 
Table 4. Association between follow up adherences and selected variables

\begin{tabular}{|c|c|c|c|c|c|}
\hline \multirow{2}{*}{ Variables } & \multicolumn{3}{|c|}{ Level of Adherence } & \multirow{2}{*}{$x^{2}$ value } & \multirow{2}{*}{$\mathrm{p}$-value } \\
\hline & Good & Fair & Poor & & \\
\hline \multicolumn{6}{|l|}{ Education level } \\
\hline Can't read and write & $44(44.9 \%)$ & 19(19.4\%) & $35(35.7 \%)$ & 18.631 & $0.005^{*}$ \\
\hline Primary level & $69(52.7 \%)$ & $23(17.6 \%)$ & $39(29.7 \%)$ & & \\
\hline Secondary level & $69(65.8 \%)$ & $18(17.1 \%)$ & 18(17.1\%) & & \\
\hline Higher secondary level and above & $62(70.5 \%)$ & $10(11.3 \%)$ & $16(18.2 \%)$ & & \\
\hline \multicolumn{6}{|l|}{ Occupation } \\
\hline Service & 43(63.2\%) & $12(17.7 \%)$ & $13(19.1 \%)$ & 22.044 & $0.015^{*}$ \\
\hline Business & $48(55.2 \%)$ & $17(19.5 \%)$ & $22(25.3 \%)$ & & \\
\hline Agriculture & $25(39.1 \%)$ & $10(15.6 \%)$ & $29(45.3 \%)$ & & \\
\hline Homemaker & $76(58.5 \%)$ & $24(18.5 \%)$ & $30(23.1 \%)$ & & \\
\hline Retired & $33(70.2 \%)$ & $5(10.6 \%)$ & $9(19.2 \%)$ & & \\
\hline Unemployed & 19(73.1\%) & $2(7.7 \%)$ & $5(19.2 \%)$ & & \\
\hline \multicolumn{6}{|l|}{ Duration of DM in years } \\
\hline$<1$ & 18(36.8\%) & $8(16.3 \%)$ & $23(46.9 \%)$ & 28.063 & $<0.001 *$ \\
\hline $1-5$ & $88(56.1 \%)$ & $20(12.7 \%)$ & $49(31.2 \%)$ & & \\
\hline $5-10$ & 63(58.9\%) & $25(23.3 \%)$ & 19(17.8\%) & & \\
\hline$>10$ & $75(68.8 \%)$ & $17(15.6 \%)$ & $17(15.6 \%)$ & & \\
\hline \multicolumn{6}{|l|}{ Frequency of follow up visit } \\
\hline Every 3 monthly & $126(64.6 \%)$ & $26(13.3 \%)$ & $43(22.1 \%)$ & 18.641 & $0.017^{*}$ \\
\hline Every 6 monthly & $14(42.4 \%)$ & $12(36.4 \%)$ & $7(21.2 \%)$ & & \\
\hline Yearly & $8(40 \%)$ & $3(15 \%)$ & $9(45 \%)$ & & \\
\hline As per advice & $51(52.5 \%)$ & $18(18.6 \%)$ & $28(28.9 \%)$ & & \\
\hline As per need & $45(58.4 \%)$ & $11(14.3 \%)$ & $21(27.3 \%)$ & & \\
\hline \multicolumn{6}{|l|}{ Attended diabetic counseling } \\
\hline Yes & $175(64.6 \%)$ & $38(14 \%)$ & $58(21.4 \%)$ & 14.179 & $<0.001 *$ \\
\hline No & 69(45.7\%) & $32(21.2 \%)$ & $50(33.1 \%)$ & & \\
\hline \multicolumn{6}{|l|}{ Knowledge Level } \\
\hline Adequate (>75\%) & $111(72.1 \%)$ & $24(15.6 \%)$ & $19(12.3 \%)$ & 33.797 & $<0.001 *$ \\
\hline Moderate (50-75\%) & $101(55.2 \%)$ & $30(16.4 \%)$ & $52(28.4 \%)$ & & \\
\hline Inadequate (<50\%) & 32(37.7\%) & $16(18.8 \%)$ & $37(43.5 \%)$ & & \\
\hline
\end{tabular}

Table 4. Association between adherence to therapeutic regimen and glycemic control

\begin{tabular}{|c|c|c|c|c|}
\hline \multirow[b]{2}{*}{ Variables } & \multicolumn{2}{|c|}{ Fasting blood sugar level } & \multirow[b]{2}{*}{$\chi^{2}$ value } & \multirow[b]{2}{*}{$\mathrm{p}$-value } \\
\hline & $\begin{array}{l}\text { Good controlled } \\
(\leq 130 \mathrm{mg} / \mathrm{dl})\end{array}$ & $\begin{array}{l}\text { Poor controlled } \\
\text { (>130mg/dl) }\end{array}$ & & \\
\hline $\begin{array}{l}\text { Dietary adherence } \\
\text { Good } \\
\text { Fair } \\
\text { Poor }\end{array}$ & $\begin{array}{c}46(67.6 \%) \\
167(59.2 \%) \\
40(55.6 \%)\end{array}$ & $\begin{array}{l}22(32.4 \%) \\
115(40.8 \%) \\
32(44.4 \%)\end{array}$ & 2.320 & 0.31 \\
\hline $\begin{array}{l}\text { Exercise adherence } \\
\text { Good } \\
\text { Fair } \\
\text { Poor }\end{array}$ & $\begin{array}{l}28(75.7 \%) \\
46(70.8 \%) \\
179(55.9 \%)\end{array}$ & $\begin{array}{c}9(24.3 \%) \\
19(29.2 \%) \\
141(44.1 \%)\end{array}$ & 9.126 & $0.01 *$ \\
\hline $\begin{array}{l}\text { Medicine adherence } \\
\text { Good } \\
\text { Fair }\end{array}$ & $\begin{array}{c}59(51.3 \%) \\
183(63.3 \%)\end{array}$ & $\begin{array}{c}56(48.7 \%) \\
106(36.7 \%)\end{array}$ & 4.946 & $0.03^{*}$ \\
\hline $\begin{array}{l}\text { Follow up adherence } \\
\text { Good } \\
\text { Fair } \\
\text { Poor }\end{array}$ & $\begin{array}{l}161(66 \%) \\
37(52.9 \%) \\
55(50.9 \%)\end{array}$ & $\begin{array}{c}83(34 \%) \\
33(47.1 \%) \\
53(49.1 \%)\end{array}$ & 8.829 & $0.01 *$ \\
\hline
\end{tabular}


those involved in service (26.4\%) had good dietary adherence. Similar to this, Parajuli et al. ${ }^{7}$ found that male participants and knowledge on diabetes mellitus adhered more to their diet. Regarding exercise, sex, attended in diabetic counseling history of hospitalization due to diabetes mellitus, and level of knowledge tends to significantly affect in exercise compliance in present study $(p<0.05)$. Divya and Nadig ${ }^{19}$ reported that patients were more compliant to dietary directions than instructions on exercise. But, contradictory finding with this study was presented by Ganiyu et al. ${ }^{16}$ in which exercise adherence level was higher in the respondents with positive family history of diabetes (65.9\%) as compared to those with no family history of diabetes. The study conducted in Egypt revealed the adherence rates to medication, dietary, exercise and appointment were suboptimal. ${ }^{20}$ In Nepal, determinants for non adherence to physical activity were negative family history of DM, divorced status, lower socioeconomic class. ${ }^{7}$ Though adherence to dietary recommendations is important for effective therapy, ${ }^{21}$ lifestyle change is the most difficult and problematic part of the treatment. Many patients tend to follow medical and dietary recommendations selectively. ${ }^{22}$ In order to facilitate dietary compliance, patients' readiness and willingness to adopt changes is important. ${ }^{23}$

In present study, 28.5\% respondent had good medicine adherence and $71.5 \%$ had fair adherence and it was associated with respondents attending in diabetic counseling $(p=0.03)$. Though age and duration of diabetes were not associated with medicine adherence Marinho, et al. ${ }^{17}$ found that younger age and longer duration of diabetes were independently associated with better medication adherence. Similar finding was presented by Imran and Plathottam ${ }^{24}$ in which $61 \%$ respondents were non-adherent with medication; $18 \%$ were moderately adherent and $21 \%$ were adherent to treatment respectively. Regarding associated factors, inconsistent with present study, males (72\%) and employed respondents (69\%), were more non adherent in medicine compliance. Kasznicki et al. ${ }^{25}$ stated that the most important factors affecting patient compliance with drug therapy included patient knowledge about the treatment of diabetes $(p=0.005 ; O R, 13.89)$ and inadequate patient knowledge and awareness about the importance of adherence in the diabetes management as mentioned by Divya and Nadig. ${ }^{19}$ Research has shown better adherence for medication used than for lifestyle change. This might be the reason that patient may find easy to adhere medication schedule than diet and exercise. ${ }^{26}$

In this study, regarding follow up adherence, 57.8\% had good, $16.6 \%$ had fair and $25.6 \%$ had poor follow up adherence and there was the significance association between education $(p=0.005)$ occupation $(p=0.01)$, attended diabetic counseling $(p<0.001)$, duration of diabetes mellitus, frequency of follow up visit, and level of knowledge with follow up adherence. Contradictory to present findings, it was further supported by Lafta, Faiq and Alkaseer, ${ }^{27}$ Kalyango, Owinoand Nambuya ${ }^{9}$ and Yigazu and Desse. ${ }^{28}$

Regarding association between adherence to therapeutic regimen with glycemic control revealed that respondents with good exercise $(75.7 \%)$ adherence, fair medicine adherence $(63.3 \%)$ and good follow up adherence (66\%) had controlled fasting blood sugar level $(p=0.01, p=0.03$ and $p=0.01$ respectively). Contradictory to present findings, Lafta, Faiq, \& Alkaseer ${ }^{27}$ showed only $26 \%$ of those respondents with good follow up compliance had good glycemic control. Tan, Juliana, and Sakinah ${ }^{23}$ found significant association between dietary compliance and the FBS level $(p=0.007)$. A study done by Shrestha et al. ${ }^{29}$ revealed that $50 \%$ respondents had follow up compliance in Dharan, Nepal. Padma et al ${ }^{30}$ mentioned that following a controlled diet, regular exercise and compliance with drugs were significantly associated with achieving glycemic control.

Only one institution of study setting, purposive sampling method and self reported verbal responses to measure adherence to therapeutic regimen were the limitation of this study.This finding might be useful for hospital authority and other diabetic clinic of all health care centers to develop guidelines for educational strategies that can be used to increase adherence and glycemic control.

\section{CONCLUSION}

Adherence to diet and exercise was found inadequate in comparison with medicine and follow up visit. Further patients with good and fair adherence to exercise, medicine and follow up visit had significantly associated with good blood sugar control. As different variables were associated with therapeutic adherence, it is recommended to healthcare professionals to focus on diabetic counseling in diet and exercise adherence considering to sex, education level, duration of diabetes, diabetes knowledge level which would be of great benefit in glycemic control.

\section{CONFLICT OF INTEREST}

None declared.

\section{REFERENCES}

1. Attyia AA, El Bahnasy RE, Salem ME et al. Compliance of diabetic patients with the prescribed clinical regimen. Menoufia Med J. 2013 Jun 1;26(1):54.

2. International Diabetes Federation. IDF Diabetes Atlas, 9th edn. Brussels, Belgium: 2019. Available at: https://www.diabetesatlas.org. 
[Accessed 21st July, 2020]

3. International Diabetes Federation (IDF) Diabetes in South-East Asia. Available at: https://www.idf.org/our-network/regions-members/ south-east-asia/diabetes-in-sea.html. [Accessed 21st July, 2020]

4. International Diabetes Federation (IDF) SEA members. Available at: https://www.idf.org/our-network/regions-members/south-eastasia/members/97-nepal.html. [Accessed 21st July, 2020]

5. World Health Organization (2003): Adherence to long term therapies. Evidence for action. Geneva:

6. Cramer JA. A systematic review of adherence with medications for diabetes. Diabetes Care. 2004, 27(5): 1218-24.

7. Parajuli J, Saleh F, Thapa N et al. Factors associated with nonadherence to diet and physical activity among Nepalese type 2 diabetes patients; a cross sectional study. BMC Res Notes. 2014 Dec 1;7(1):758.

8. Albuquerque C, Correia C, Ferreira M. Adherence to the therapeutic regime in person with type 2 diabetes. Procedia Soc and Behav Sci. $2015 \operatorname{Jan} 16 ; 171: 350-8$.

9. Kalyango JN, Owino E, Nambuya AP. Non-adherence to diabetes treatment at Mulago Hospital in Uganda: prevalence and associated factors. Afr. Health Sci. 2008; 8(2).

10. Gyawali B, Ferrario A, Van Teijlingen E et al. Challenges in diabetes mellitus type 2 management in Nepal: a literature review. Glob. Health Action. 2016 Dec 1;9(1):31704.

11. Morisky DE, Green LW, Levine DM. Concurrent and predictive validity of a self-reported measure of medication adherence. Med. Care. $1986 \operatorname{Jan}$ 1:67-74.

12. American Diabetes Association. Standards of medical care in diabetes - 2013. Diabetes Care. 2013 Jan; 36(Suppl 1):S11.

13. Klinovszky A, Kiss IM, Papp-Zipernovszky 0 et al. Associations of different adherences in patients with type 2 diabetes mellitus. Patient Prefer. Adherence. 2019;13:395.

14. Mirahmadizadeh $A$, Khorshidsavar $H$, Seif $M$ et al.Adherence to Medication, Diet and Physical Activity and the Associated Factors Amongst Patients with Type 2 Diabetes. Diabetes Ther. 2020 Feb 1;11(2):479-94.

15. Sharma T, Kalra J, Dhasmana D et al. Poor adherence to treatment: A major challenge in diabetes. J. Indian Acad. Clin. Med. 2014; 15(1): 26-9.

16. Ganiyu AB, Mabuza LH, Malete NH et al. Non-adherence to diet and exercise recommendations amongst patients with type 2 diabetes mellitus attending Extension II Clinic in Botswana. Afr. J. Prim. Health Care Fam. Med. 2013;5(1).

17. Marinho FS, Moram C, Rodrigues PC et al.Treatment adherence and its associated factors in patients with type 2 diabetes: results from the Rio de Janeiro type 2 diabetes cohort studies. J. Diabetes Res. 2018 Jan 1;2018.

18. Bonger Z, Shiferaw S, Tariku EZ. Adherence to diabetic self-care practices and its associated factors among patients with type 2 diabetes in Addis Ababa, Ethiopia. Patient Prefer. Adherence. 2018;12:963.

19. Divya $S$ and Nadig P.Factors contributing to non-adherence to medication among type 2 diabetes mellitus in patients attending tertiary care hospital in South India. Asian J Pharm Clin Res. 2015:18 (2), 274-76

20. Shams ME, Barakat EA. Measuring the rate of therapeutic adherence among outpatients with T2DM in Egypt. Saudi Pharm J. 2010 Oct 1;18(4):225-32.

21. Jaworski $M$, Panczyk $M$, Cedro $M$ et al.. Adherence to dietary recommendations in diabetes mellitus: disease acceptance as a potential mediator. Patient Prefer. Adherence. 2018;12:163.

22. Ahola AJ, Groop PH. Barriers to self management of diabetes. Diabet Med. 2013 Apr;30(4):413-20.

23. Tan SL, Juliana S, Sakinah H. Dietary compliance and its association with glycemic control among poorly controlled type 2 diabetic outpatients in Hospital Universiti Sains Malaysia. Malays. J. Nutr. 2011 Dec 1;17(3).

24. Imran M, Plathottam JJ. .A study on treatment adherence among patients with type 2 diabetes mellitus attending diabetic clinic. Int J Community Med Public Health. 2017;4(5):1701-1703.

25. Kasznicki J, Głowacka A, Drzewoski J. Type 2 diabetic patients compliance with drug therapy and glycaemic control. Diabetol Dośw Klin. 2007 Jul 18;7(4):199-8.

26. Sontakke S, Jadhav M, Pimpalkhute $S$ et al.. Evaluation of adherence to therapy in patients of type 2 diabetes mellitus. J Young Pharm. 2015 Oct 1;7(4):462.

27. Lafta RK, Faiq U, Al-Kaseer AH. Compliance of Diabetic patients. Mustansiriya Med J. 2008;7(2):17-22.

28. Yigazu DM, Desse TA. Glycemic control and associated factors among type 2 diabetic patients at Shanan Gibe Hospital, Southwest Ethiopia. BMC Res Notes. 2017 Dec;10(1):1-6.

29. Shrestha JS, Shrestha A, Ghimire A et al. A Study Method of Treatment Compliance in Regular Follow up, Routine Investigation and Complication Screening among Diabetic Patients Presenting in BPKIHS, Dharan. J Endocrinol Diabetes Obes. 2017; 5(1): 1096.

30. Padma K, Bele SD, Bodhare TN et al. Evaluation of knowledge and self-care practices in diabetic patients and their role in disease management. National Journal of Community Medicine. 2012 Jan;3(1):3-6. 